\title{
A Rare Case Report of Out of the Ordinary Canal of Nuck Hernia Encompassing Pelvic Structures, Showing up as a Labial Mass
}

\author{
Neha Bagri ${ }^{1}$, Ritu Misra ${ }^{2}$
}

\begin{abstract}
Aim and objective: We report a rare case of the canal of Nuck hernia containing part of the uterus and both ovaries as its contents. The aim is to build up the awareness of this condition by reviewing the ultrasound and MRI imaging findings and identification of prolapsed ovary with correct knowledge of the entity and focused analysis.

Background: The patent canal of Nuck is one of the rare developmental entities in females. Hernia of the canal of Nuck is an extension of the peritoneal fold through the inguinal canal up to the labia majora. Defective obliteration of this peritoneal fold leads to herniation of abdominal content into the inguinal canal.

Case description: An exceptionally rare case of a 5-month-old female child who presented to us with a palpable, non-tender, left labial mass. Ultrasound and MRI were performed showing the contents of herniating sac as uterine fundus and bilateral ovaries along with minimal free fluid. The infant was managed conservatively and kept under follow-up.

Conclusion: Incidence of both ovary and uterus as contents of hernia is very rare. Furthermore, early and correct identification of the herniated ovary prevents an uncalled-for surgery.

Clinical significance: It is very important to be familiar with this entity, especially in cases of ovarian hernia due to the risk of associated complications like incarceration and torsion.

Keywords: Canal of Nuck, Hernia, Inguinal canal, Ovary, Uterus.

Journal of Mahatma Gandhi University of Medical Sciences \& Technology (2021): 10.5005/jp-journals-10057-0147
\end{abstract}

\section{BACKGROUND}

Canal of Nuck anomalies is an uncommon but significant cause of morbidity in females $<5$ years of age. In females, the canal of Nuck, comparable to the male processus vaginalis, is a protrusion of the parietal peritoneum that connects between the inguinal canal and labia majora. This peritoneal fold classically gets effaced as a fibrous cord during the first year of life. ${ }^{1}$ However, sometimes, the canal fails to close partially or completely, resulting in a hydrocele or herniation of pelvic contents.

Inguinal hernia is more among men as compared to females. The male to female ratio is $7: 1 .^{2}$

\section{Case Description}

We report an exceptionally rare case of a 5-month-old female child who presented with a palpable, non-tender, left labial mass. Clinical examination revealed reducible left groin swelling extending to the upper part of labium majora (Fig.1). There were no signs of obstruction or strangulation. A clinical diagnosis of left congenital inguinal hernia was made. A focused ultrasound of the left inguinal region was performed which revealed a sac herniating into the left labia through the left inguinal canal via the patent canal of Nuck. The herniating sac contained an homogeneous solid mass-like structure, which represented the uterine fundus and two small ovoid structures containing tiny cysts representing normal follicles in both ovaries. Minimal free fluid was also seen in the herniating sac. On color Doppler ultrasound, the presence of blood flow was seen in the uterus and ovaries excluding the possibility of ovarian torsion. MRI was performed the next day with the acquisition of coronal and sagittal T2-weighted images, which confirmed the
1,2Department of Radiodiagnosis, Vardhman Mahavir Medical College and Safdarjung Hospital, New Delhi, India

Corresponding Author: Neha Bagri, Department of Radiodiagnosis, Vardhman Mahavir Medical College and Safdarjung Hospital, New Delhi, India, Phone: +91 9013606279, e-mail: drnehabagri@gmail.com How to cite this article: Bagri N, Misra R. A Rare Case Report of Out of the Ordinary Canal of Nuck Hernia Encompassing Pelvic Structures, Showing up as a Labial Mass. J Mahatma Gandhi Univ Med Sci Tech 2021;6(2):69-71.

Source of support: Nil

Conflict of interest: None

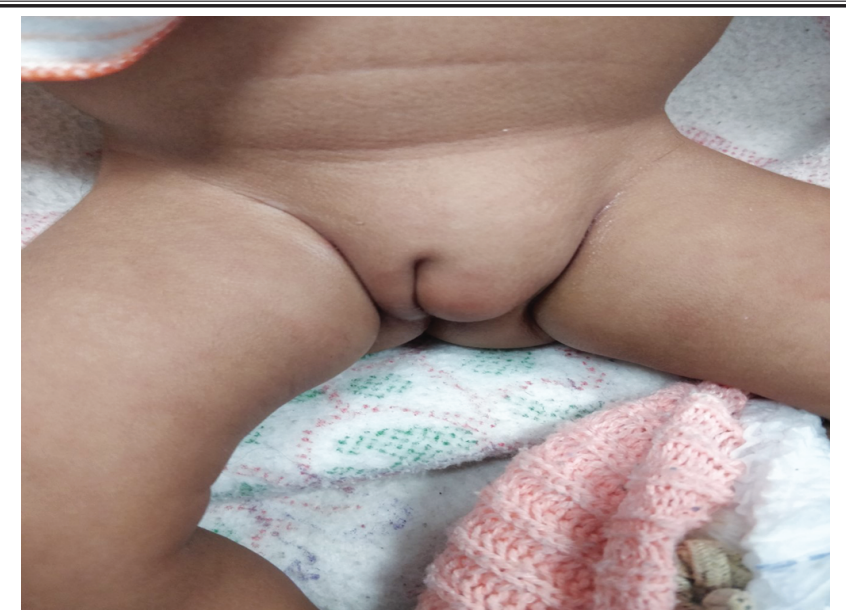

Fig. 1: A 5-month-old female child presented to our department with a left labial mass

(0) The Author(s). 2021 Open Access This article is distributed under the terms of the Creative Commons Attribution 4.0 International License (https:// creativecommons.org/licenses/by-nc/4.0/), which permits unrestricted use, distribution, and non-commercial reproduction in any medium, provided you give appropriate credit to the original author(s) and the source, provide a link to the Creative Commons license, and indicate if changes were made. The Creative Commons Public Domain Dedication waiver (http://creativecommons.org/publicdomain/zero/1.0/) applies to the data made available in this article, unless otherwise stated. 

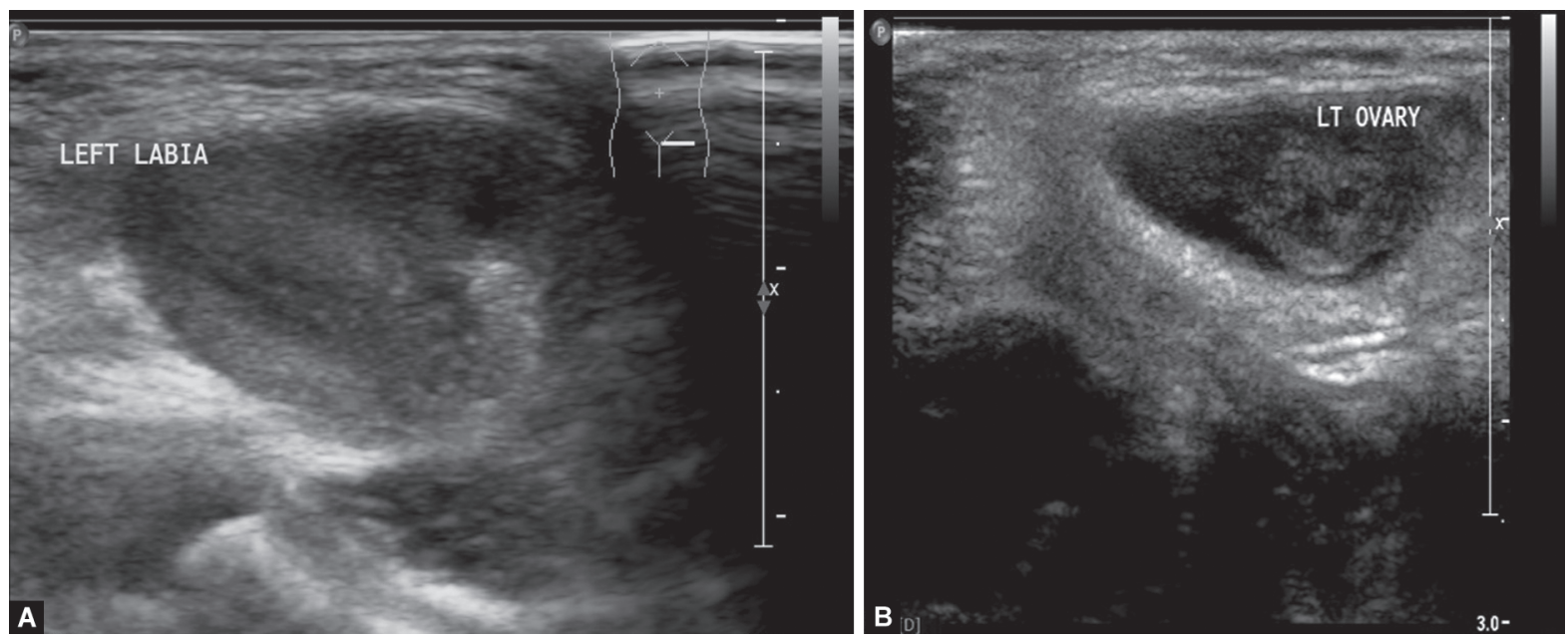

Figs $2 \mathrm{~A}$ and B: Ultrasound image demonstrating transverse views of the left inguinal region showing the canal of Nuck hernia containing the right and the left ovary

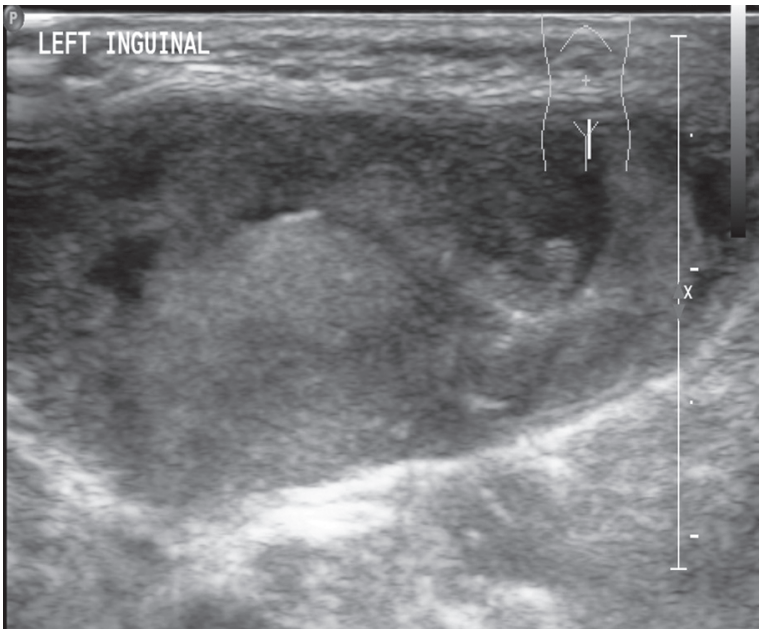

Fig. 3: Ultrasound image demonstrating sagittal view of the left inguinal region showing the canal of Nuck hernia containing the uterus, the right ovary, and the left ovary

presence of a hernia sac containing uterus and both ovaries in the left inguinal canal, extending into the left labia through the patent canal of Nuck. The infant was managed conservatively and kept under follow-up (Figs 2 to 4).

\section{Discussion}

The most common inguinal hernias encountered during infancy are indirect inguinal hernias. Indirect inguinal hernias arise due to protrusion of abdominal contents through the deep inguinal ring, lateral to the inferior epigastric vessels, because of failure of closure of the embryonic processus vaginalis leading to the patent inguinal canal. In females, a patent inguinal canal is called a canal of Nuck.

The processus vaginalis is a tubular peritoneal fold that invaginates into the inguinal canal. It develops around 24 weeks of gestation and, in female infants, closes around 32 weeks of gestation. This process of closure proceeds gradually in a superiorto-inferior direction. ${ }^{3}$

The pelvic structures, such as bowel, omental fat, fluid, ovary, fallopian tube, rarely the uterus, and the urinary bladder herniate into the canal of Nuck, through the inguinal canal to the labia major. Among all the canal of Nuck hernias reported during infancy, $15-20 \%$ contain ovaries as their content. ${ }^{4}$ However, herniation of the uterus is extremely rare. Few cases have been reported showing a higher association of certain syndromes, such as androgen insensitivity syndrome and Mayer-Rokitansky-Kuster-Hauser syndrome with canal of Nuck hernias containing ovary, testis, or uterine parts. $^{5}$

Ultrasound is an easily available, radiation-free, worthwhile, and highly accurate imaging modality for evaluating inguinal lesions. Ultrasound with a high-frequency transducer provides excellent spatial resolution for the characterization of inguinal lesions. In the present case, ultrasonographic identification of peripheral small cysts, representing follicles was helpful for the diagnosis of the ovarian tissue as hernia sac contents. The presence of soft tissue masses containing multiple small cysts of varying size on ultrasound is a useful feature for the recognition of ovary containing hernias. ${ }^{6}$

When the inguinal hernia contains the ovary as its content, early diagnosis becomes very important because incarceration of the ovary is common which is at risk of torsion in neonates. ${ }^{7}$ In ovarian torsion, venous and lymphatic return of the ovary is impaired, causing increased pressure and swelling within the canal of Nuck, which is accompanied by other symptoms such as abdominal pain and vomiting. Ultrasound signs of ovarian torsion are heterogeneous diffusely enlarged, mass-like ovary containing multiple peripheral cysts and absence of ovarian blood flow on color Doppler examination. ${ }^{8} \mathrm{MRI}$ may be done to know the exact nature of contents in case ultrasound is inconclusive. In our case, it was done to confirm the ultrasound findings and better anatomical and soft-tissue delineation.

The most common differential diagnosis is the hydrocele of the canal of Nuck which can coexist in about one-third of cases. Other possibilities to be considered are lipoma, lymphadenopathy, cold abscess, hematoma, rarely cystic lymphangioma, neuroblastoma metastasis to the groin, and ganglion. ${ }^{9}$

\section{Conclusion}

It is crucial to diagnose the canal of Nuck hernia containing the ovary, as it carries a risk of ovarian torsion. The primary and preferred modality in the evaluation of inguinal masses is ultrasound, as it 


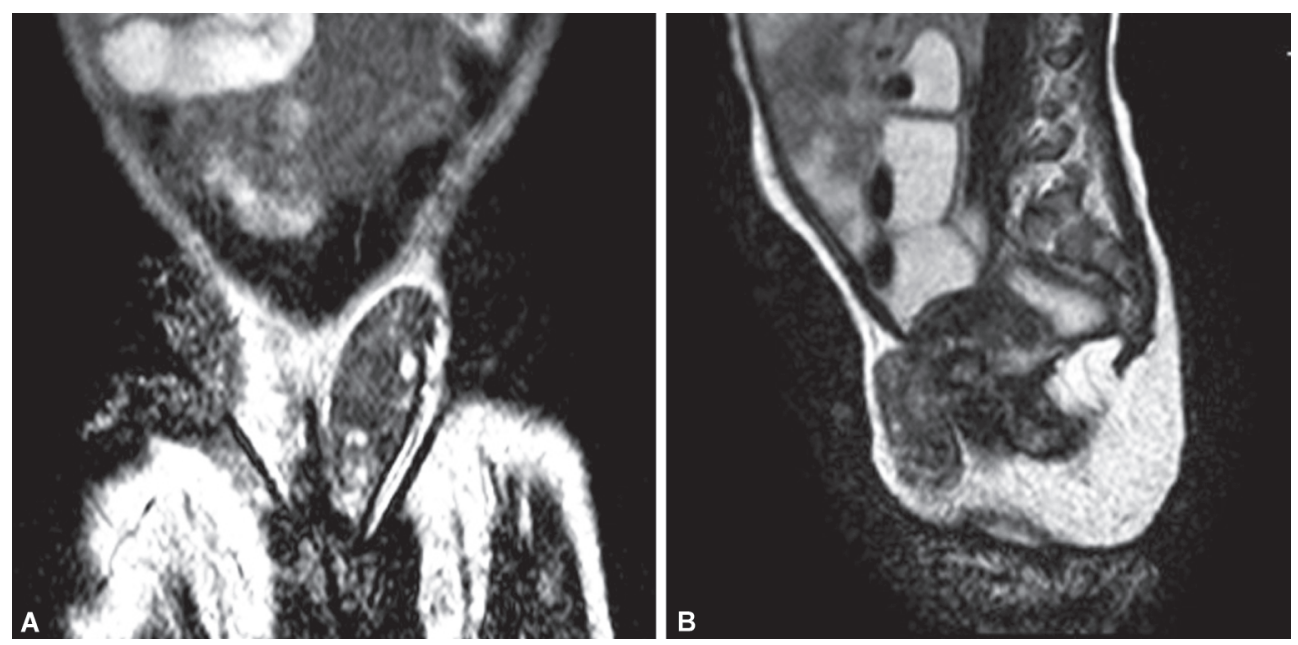

Figs 4A and B:T2W coronal and sagittal images showing the canal of Nuck hernia containing the uterus, the right ovary, and the left ovary in the left inguinal region

depicts the contents well and hastens the surgical planning. The patent canal of Nuck may allow the ovary to enter the inguinal region but, the presence of the uterus as its content in the inguinal hernia sac is very unusual and rare. The case is presented due to its rarity of presentation.

\section{Clinical Significance}

Incidence of both ovary and uterus as contents of hernia is very rare. Furthermore, early and correct identification of the herniated ovary prevents an uncalled-for surgery. It is very important to be familiar with this entity, especially in cases of ovarian hernia due to the risk of associated complications like incarceration and torsion.

\section{ACKnOWLedgments}

We would like to acknowledge the staff of our department for assistance with our imaging needs.

\section{References}

1. Jedrzejewski G, Stankiewicz A, Wieczorek AP. Uterus and ovary hernia of the canal of nuck. Pediatr Radiol 2008;38(11):1257-1258. DOI: 10.1007/s00247-008-0959-x.
2. Sangwan M, Sangwan V, Garg M, et al. Abdominal wall hernia in rural population in India-spectrum changing? Open J Epidemiol 2013;3(03):135-138. DOI: 10.4236/ojepi.2013.33020.

3. Rees MA, Squires JE, Tadros S, et al. Canal of nuck hernia: a multimodality imaging review. Pediatr Radiol 2017;47(8):893. DOI: 10.1007/s00247-017-3853-6.

4. Thomas AK, Clint TT, Jancelewicz T, et al. Canal of nuck hernia containing pelvic structures presenting as a labial mass. Radiol Case Rep 2018;13(3):534-536. DOI: 10.1016/j.radcr.2018.02.007.

5. Choi KH, Baek HJ. Incarcerated ovarian herniation of the canal of nuck in a female infant: ultrasonographic findings and review of literature. Ann Med Surg 2016;9:38-40. DOI: 10.1016/j.amsu.2016.06.003.

6. Narcı A, Korkmaz M, Albayrak R, et al. Preoperative sonography of nonreducible inguinal masses in girls. J Clin Ultrasound 2008;36(7):409-412. DOI: 10.1002/jcu.20422.

7. Laing FC, Townsend BA, Rodriguez JR. Ovary containing hernia in a premature infant: Sonographic diagnosis. J Ultrasound Med 2007;26(7):985-987. DOI: 10.7863/jum.2007.26.7.985.

8. Ravikanth R, Kamalasekar K. Left ovary containing hernia of the canal of nuck and right inguinal hernia with small bowel loops in a 12-dayold newborn girl: a rarity. J Med Ultrasound 2019;27(3):158-159. DOI: 10.4103/JMU.JMU_96_18.

9. Dholakia M, Singh G, Kore R, et al. Hernia of canal of nuck: some considerations. Med J DY Patil Univ 2015;8(6):833-835. DOI: 10.4103/0975-2870.169929. 